\title{
Diabetes Management Experience and the State of Hypoglycemia: National Online Survey Study
}

Karim Zahed ${ }^{1}$, BS, MSc; Farzan Sasangohar ${ }^{1,2}$, BA, BCS, MASc, SM, PhD; Ranjana Mehta ${ }^{1}$, BSc, MSc, PhD; Madhav Erraguntla $^{1}$, BTECH, MTECH, PhD; Khalid Qaraqe ${ }^{3}$, BS, MS, PhD

${ }^{1}$ Department of Industrial and Systems Engineering, Texas A\&M University, College Station, TX, United States

${ }^{2}$ Center for Outcomes Research, Houston Methodist Hospital, Houston, TX, United States

${ }^{3}$ Department of Electrical and Computer Engineering, Texas A\&M University at Qatar, Doha, Qatar

\section{Corresponding Author:}

Farzan Sasangohar, BA, BCS, MASc, SM, PhD

Department of Industrial and Systems Engineering

Texas A\&M University

3131 TAMU

College Station, TX, 77843

United States

Phone: 19794582337

Email: sasangohar@tamu.edu

\section{Abstract}

Background: Hypoglycemia, or low blood sugar levels, in people with diabetes can be a serious life-threatening condition, and serious outcomes can be avoided if low levels of blood sugar are proactively detected. Although technologies exist to detect the onset of hypoglycemia, they are invasive or costly or exhibit a high incidence of false alarms. Tremors are commonly reported symptoms of hypoglycemia and may be used to detect hypoglycemic events, yet their onset is not well researched or understood.

Objective: This study aimed to understand diabetic patients' perceptions of hypoglycemic tremors, as well as their user experiences with technology to manage diabetes, and expectations from a self-management tool to ultimately inform the design of a noninvasive and cost-effective technology that detects tremors associated with hypoglycemia.

Methods: A cross-sectional internet panel survey was administered to adult patients with type 1 diabetes using the Qualtrics platform in May 2019. The questions focused on 3 main constructs: (1) perceived experiences of hypoglycemia, (2) experiences and expectations about a diabetes management device and mobile app, and (3) beliefs and attitudes regarding intention to use a diabetes management device. The analysis in this paper focuses on the first two constructs. Nonparametric tests were used to analyze the Likert scale data, with a Mann-Whitney $U$ test, Kruskal-Wallis test, and Games-Howell post hoc test as applicable, for subgroup comparisons to highlight differences in perceived frequency, severity, and noticeability of hypoglycemic tremors across age, gender, years living with diabetes, and physical activity.

Results: Data from 212 respondents (129 [60.8\%] females) revealed statistically significant differences in perceived noticeability of tremors by gender, whereby males noticed their tremors more $(P<.001)$, and age, with the older population reporting lower noticeability than the young and middle age groups $(P<.001)$. Individuals living longer with diabetes noticed their tremors significantly less than those with diabetes for $\leq 1$ year but not in terms of frequency or severity. Additionally, the majority of our participants $(150 / 212,70.7 \%)$ reported experience with diabetes-monitoring devices.

Conclusions: Our findings support the need for cost-efficient and noninvasive continuous monitoring technologies. Although hypoglycemic tremors were perceived to occur frequently, such tremors were not found to be severe compared with other symptoms such as sweating, which was the highest rated symptom in our study. Using a combination of tremor and galvanic skin response sensors may show promise in detecting the onset of hypoglycemic events.

(JMIR Diabetes 2020;5(2):e17890) doi: $\underline{10.2196 / 17890}$

\section{KEYWORDS}

tremor; hypoglycemia; diabetes mellitus; remote sensing technology; survey methods; mobile phone 


\section{Introduction}

\section{Background}

Diabetes is a chronic disease affecting more than $9.4 \%$ of the world's population [1], with an estimated US $\$ 327$ billion in economic costs each year [2]. The majority (about 90\%) of the population living with diabetes has type 2 diabetes mellitus (T2DM), while about $10 \%$ have type 1 diabetes mellitus (T1DM). Collectively, both types are responsible for around $12 \%$ of annual deaths in the United States alone [3]. The management of diabetes is burdensome and requires regular monitoring of blood sugar and careful attention to nutrition.

Fluctuating blood sugar levels outside the normal ranges tend to be common among people with T1DM [4]. Hypoglycemia or low blood glucose (BG) is a dangerous condition that affects people with diabetes when the blood glucose level falls below $70 \mathrm{mg} / \mathrm{dL}$ [5]. If the BG level continues to fall below $54 \mathrm{mg} / \mathrm{dL}$, it may result in severe hypoglycemia [5]. Values below this level can cause severe cognitive impairment, seizure, loss of consciousness, and, in some cases, coma [6]. Severe hypoglycemia has also been associated with a higher mortality rate. In one study, $10 \%$ of the children surveyed had passed away by the time of follow-up [7]. Over time, recurrent hypoglycemia can inhibit the associated symptoms, leading the affected person to lose sensitivity to or become unaware of hypoglycemic symptoms [6]. When the body is unable to secrete epinephrine that generates hypoglycemic symptoms [8], the risk of death could increase by more than 3 -fold [9]. This is particularly risky during sleep where nocturnal hypoglycemia leads to cases of "dead in bed" [10]. Despite evidence suggesting the existence of such self-unawareness and lost sensitivity to hypoglycemic symptoms, little research exists to document the extent of such a phenomenon among patients with diabetes.

The most prevalent technology to monitor BG, particularly for T2DM, is blood glucose meters, which require manual application of a test strip (typically by pricking a finger). The main limitation of traditional meters is that the measurement is periodic and manual. Continuous glucose monitors (CGMs) were commercialized at the beginning of this century [11] and have gained popularity especially among patients with T1DM as they are capable of monitoring BG levels continuously and autonomously. CGMs can provide information about BG trends and can warn against the onset of hyper- and hypoglycemia. However, these tools are invasive and costly and require regular maintenance and calibration [12]. In a large survey of patients with T1DM, around a third of the sample used CGMs [13], and in another survey of 877 CGM users, nearly half noted that they were not satisfied with the cost [14]. More recent studies also showed that CGMs in many cases are not cost-effective $[15,16]$, which generally limits their utility, particularly in medically underserved areas where there is less access to health care [17], less health and technological literacy [18], and, in many cases, a low socioeconomic status. Therefore, there is a critical need to have affordable, noninvasive alternative methods and technologies for monitoring and self-management of diabetes and early detection of hypoglycemic onsets. However, the availability of alternatives, particularly for detection and monitoring of hypoglycemia, has been very limited. A few noninvasive devices such as HypoMon, GlucoWatch G2, and Diabetes Sentry made it to the market but exhibited a high incidence of false alarms and were sensitive to environmental conditions [19]. Those that could not be commercialized were prototypes with significant wearability issues [19]. One study even claimed that noninvasive options were incapable of competing with invasive methods in terms of accuracy [20]. Our overall research objective is to address this gap by designing a noninvasive and cost-effective technology that detects tremors associated with hypoglycemia.

\section{Objectives}

In a previous review, we reported that tremors and trembling have been found to be very common among patients with diabetes [19]. In another study surveying elderly subjects, trembling was reported in $71 \%$ of patients with diabetes [21]. Tremors have been shown to be a significant symptom of hypoglycemia in several other survey studies [22-25] as well as in laboratory studies [26,27]. In this paper, we documented findings from a large survey of patients with T1DM regarding their perception of hypoglycemic symptoms. In particular, we highlighted the differences in how patients perceive the frequency of occurrence, severity, and noticeability of hypoglycemic tremors across age, gender, years living with diabetes, and physical activity to inform the design of future interventions. Additionally, we highlighted patient experiences with technologies used to monitor their blood sugar levels and their preferences for a CGM-alternative wearable device.

\section{Methods}

\section{Study Design}

A cross-sectional internet panel survey of 212 US adults with T1DM was conducted using the Qualtrics platform in May 2019. The study was conducted in accordance with STrengthening the Reporting of OBservational studies in Epidemiology (STROBE) guidelines [28]. After the institutional review board at the authors' institution reviewed and approved the study protocol, participants were recruited through a Qualtrics panel. Individuals who qualified for the survey based on self-reported demographic data ( $\geq 18$ years, diagnosed with T1DM) were invited via email to join the panel. The email included information such as the title of the survey, its duration, and a link to follow if they were interested in participating, which would increase their points that can be redeemed later for a reward. To further evaluate this criterion and assess the quality of responses, a pilot data set consisting of the first $10 \%$ of responses $(n=20)$ was shared with the research team. Additionally, an automated logic was added to the instrument to automatically remove data that were deemed unreasonable or responses that were not relevant to the question. No identifiable information was recorded, but latitude and longitude were stored by using Qualtrics for each respondent and used to confirm that all participants were located within the United States. 


\section{Survey Design}

The survey was designed to target 3 main constructs: (1) perceived experiences of hypoglycemia, (2) experiences and expectations about a diabetes management device and mobile app, and (3) beliefs and attitudes regarding the intention to use a diabetes management device. Questions targeting the first set of constructs attempted to understand the frequency and severity of hypoglycemic tremors when compared with other symptoms of hypoglycemia [29,30]. Additional questions were related to the noticeability of hypoglycemic tremors. These questions were rated by the participants on a 10-point Likert scale (eg, 1=Not Frequent, 5=Neutral, 10=Very Frequent). Questions related to a second set of constructs attempted to document the variety and prevalence of type of technologies such as smartphone apps, CGMs, insulin pumps, and the regular BG meters used for diabetes self-management. Additionally, several questions were designed to elicit patients' preference for features and characteristics of an ideal diabetes management mobile app and issues related to wearability. Finally, participants were asked about their preference for the frequency of BG measurement and the time of the day in which they preferred such a measurement. Beliefs and attitudes relating to the intention to use a device will be reported elsewhere.

\section{Analysis}

After the pilot data collection and consultation with the research team, a Qualtrics team evaluated the responses for consistency, completeness, and speed of completion. All analyses were performed using JASP (JASP Team, version 0.10.2.). Nonparametric tests were used to analyze the Likert scale data [31]. To compare noticeability, frequency of occurrence, and severity of tremors across genders, a Mann-Whitney U test was performed. To compare them across age groups, years with diabetes, and physical activity, a Kruskal-Wallis test was performed. When a significant difference was found, the analysis was followed with a Games-Howell post hoc test to identify the different groups.

\section{Results}

\section{Demographics}

Participants' demographics and comparisons with national averages are summarized in Table 1. All participants were located in the United States and represented 40 out of 50 states. Of the 212 participants, $129(60.9 \%)$ were female. A total of 117 participants were between the ages of 30 and 50 years, contributing to more than half the sample size $(55.2 \%)$. As expected, our data overrepresents the middle age groups and underrepresents older adults who might not be inclined to take a web-based survey. Other demographic factors align with the national data available. A total of 182/212 (82\%) individuals in our sample were white non-Hispanic, and 92 participants (43.4\%) had a household income greater than US \$60,000. 
Table 1. Participant demographics.

\begin{tabular}{|c|c|c|c|c|}
\hline \multirow{2}{*}{$\begin{array}{l}\text { Online data sample } \\
\text { Characteristics }\end{array}$} & \multirow[b]{2}{*}{ Values, n (\%) } & \multicolumn{2}{|l|}{ National data } & \multirow[b]{2}{*}{ References } \\
\hline & & Characteristics & Values, \% & \\
\hline Gender & & & & {$[32]$} \\
\hline Female & $129(60.9)$ & $\sim^{\mathrm{a}}$ & 51.0 & \\
\hline Male & $83(39.1)$ & - & 49.0 & \\
\hline Age (years) & & & & {$[33]$} \\
\hline $18-29$ & $34(16.0)$ & $20-29$ & 18.4 & \\
\hline $30-39$ & $64(30.2)$ & $30-39$ & 17.8 & \\
\hline $40-49$ & $53(25.0)$ & $40-49$ & 16.6 & \\
\hline $50-59$ & $33(15.6)$ & $50-59$ & 17.4 & \\
\hline$\geq 60$ & $28(13.2)$ & $\geq 60$ & 29.8 & \\
\hline Race & & & & {$[34]$} \\
\hline White & $182(85.9)$ & - & 76.5 & \\
\hline Native Hawaiian or Other Pacific Islander & $2(0.9)$ & - & 0.2 & \\
\hline Black or African American & $13(6.1)$ & - & 13.4 & \\
\hline Asian & $6(2.8)$ & - & 5.9 & \\
\hline Two or more races & $6(2.8)$ & - & 2.7 & \\
\hline Other & $3(1.4)$ & - & - & \\
\hline White non-Hispanic & $174(82.1)$ & - & 60.4 & \\
\hline Hispanic or Latino & $17(8.0)$ & - & 18.3 & \\
\hline Smartphone & & & & {$[35]$} \\
\hline None & $15(7.1)$ & - & 19.0 & \\
\hline Yes & $197(92.9)$ & - & 81.0 & \\
\hline Android & $103(52.2)$ & - & 51.1 & \\
\hline iOS & $93(47.2)$ & - & 48.1 & \\
\hline Other & $1(0.5)$ & - & 0.8 & \\
\hline Income level (US \$) & & & & {$[34]$} \\
\hline$<20,000$ & $24(11.3)$ & $<25,000$ & 19.1 & \\
\hline 20,000 to 29,999 & $20(9.4)$ & 25,000 to 35,000 & 8.8 & \\
\hline 30,000 to 39,999 & $23(10.9)$ & 35,000 to 50,000 & 12.0 & \\
\hline 40,000 to 49,999 & $17(8.0)$ & 50,000 to 75,000 & 17.2 & \\
\hline 50,000 to 59,999 & $29(13.7)$ & & & \\
\hline$>60,000$ & $92(434)$ & $>75,000$ & 42.9 & \\
\hline Did not answer & $7(33)$ & Did not answer & - & \\
\hline Educational level & & & & {$[36]$} \\
\hline Not available & - & None & 1.4 & \\
\hline Less than high school & $2(0.9)$ & - & 4.2 & \\
\hline High school & $36(17.0)$ & - & 34.9 & \\
\hline Some college, no degree & $43(20.3)$ & - & 21.0 & \\
\hline Bachelor's degree & $61(28.8)$ & - & 18.8 & \\
\hline Associate degree or trade school & $20(9.4)$ & - & 8.2 & \\
\hline Graduate or professional & $50(236)$ & - & 11.5 & \\
\hline Years living with diabetes & & & & \\
\hline
\end{tabular}




\begin{tabular}{|c|c|c|c|c|}
\hline \multirow{2}{*}{$\begin{array}{l}\text { Online data sample } \\
\text { Characteristics }\end{array}$} & \multirow[b]{2}{*}{ Values, n (\%) } & \multicolumn{2}{|l|}{ National data } & \multirow[b]{2}{*}{ References } \\
\hline & & Characteristics & Values, $\%$ & \\
\hline$\leq 1$ & $69(32.5)$ & - & - & \\
\hline$>1$ and $\leq 10$ & $46(21.7)$ & - & - & \\
\hline$>10$ and $\leq 25$ & $39(18.4)$ & - & - & \\
\hline$>25$ & $58(27.4)$ & - & - & \\
\hline \multicolumn{5}{|c|}{ Daily blood sugar measurements } \\
\hline 0 & $12(5.9)$ & - & - & \\
\hline $1-3$ & $85(41.7)$ & - & - & \\
\hline $4-10$ & $107(52.5)$ & - & - & \\
\hline
\end{tabular}

${ }^{\mathrm{a}}$ Not available.

Android users constituted 52.3\% (103/197) of smartphone users, and iOS users constituted 47.2\% (93/197), while 15 (7.1\%) participants indicated that they did not own a smartphone. Participants were also asked how many years they had lived with diabetes. More participants were recently affected ( $\leq 1$ year; $69 / 212,32.5 \%$ ) or had lived with diabetes for more than 25 years $(58 / 212,27.4 \%)$, compared with $>1$ year but $\leq 10$ years $(46 / 212,21.7 \%)$, and $>10$ years but $\leq 25$ years $(39 / 212,18.4 \%)$. Participants were also asked to provide their overall level of physical activity as highly active, active, insufficiently active, or inactive per the guidelines specified by the Office of Disease Prevention and Health Promotion (ODPHP) [37]. The ODPHP definitions were provided as a reference. Of the 212 participants, $50 / 212(23.58 \%)$ reported to be inactive, 74/212 (34.9\%) reported being insufficiently active, $65(30.6 \%)$ participants claimed to be active, and only 23/212 (10.8\%) claimed to be highly active. When participants were asked how often they measured their BG level, they reported an average of 3.51 times per day (SD 2.18; range 0-10) with around 97/212 (47.5\%) participants performing the measurements less than the required minimum of 4 times a day [38].

\section{Perception of Hypoglycemic Symptoms}

As shown in Table 2, none of the symptoms were rated as very severe or very frequent on average. However, 3 symptoms were reported to be severe (ie, had an average rating above 5). These were sweating, tingly feeling, and change in body temperature. Similarly, 4 symptoms were reported as frequent (sweating, tingly feeling, change in body temperature, and headaches). Severity and frequency were found to be positively correlated using the Spearman rank correlation $(\rho>0.8 ; P<.001)$ for all symptoms listed.

Table 2. Average reported rating of severity and frequency of occurrence of different hypoglycemic symptoms.

\begin{tabular}{|c|c|c|c|c|c|}
\hline \multirow[t]{2}{*}{ Symptoms } & \multicolumn{2}{|l|}{ Frequency $^{\mathrm{a}}$} & \multicolumn{2}{|l|}{ Severity ${ }^{b}$} & \multirow[t]{2}{*}{ Spearman correlation, $\rho$} \\
\hline & Mean (SD) & Median & Mean (SD) & Median & \\
\hline Nausea & $4.15(2.75)$ & 4 & $4.08(2.8)$ & 4 & 0.88 \\
\hline Change in saliva & $4.46(2.88)$ & 5 & $4.29(2.88)$ & 4 & 0.90 \\
\hline Tremor & $4.83(2.77)$ & 5 & $4.59(2.71)$ & 4 & 0.84 \\
\hline Headache & $5.36(2.92)$ & 6 & $4.95(2.97)$ & 5 & 0.85 \\
\hline Change in body temperature & $5.59(2.87)$ & 6 & $5.24(2.89)$ & 5 & 0.86 \\
\hline Tingly feeling in limbs & $5.76(2.82)$ & 6 & $5.26(2.74)$ & 5 & 0.82 \\
\hline Sweating & $5.95(2.78))$ & 6 & $5.75(2.81)$ & 6 & 0.84 \\
\hline
\end{tabular}

${ }^{\mathrm{a}} 1=$ extremely rare, $5=$ neither rare nor frequent, $10=$ extremely frequent.

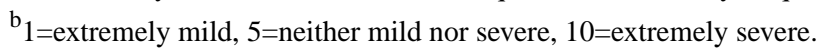

Although tremors were generally reported to have medium severity and frequency, when participants were asked how often they encounter hypoglycemic tremors, 110/212 (51.9\%) participants reported having hypoglycemic tremors at least once a week (Table 3). 
Table 3. Reported frequency of occurrence of tremors.

\begin{tabular}{ll}
\hline Tremor occurrence & Values, $\mathrm{n}(\%)$ \\
\hline Never & $11(5.2)$ \\
Rarely & $48(22.6)$ \\
Once a month & $43(20.3)$ \\
Once a week & $36(17)$ \\
Once every few days & $39(18.4)$ \\
Once a day & $24(11.3)$ \\
More than once a day & $11(5.2)$ \\
\hline
\end{tabular}

To compare the effect of hypoglycemia awareness on the perception of symptoms, the question on tremor noticeability was used to split participants into 2 groups. If tremors were rated as less noticeable $(\leq 5)$, participants were categorized as hypoglycemia impaired; otherwise, they were categorized as hypoglycemia aware. A Mann-Whitney test showed that all symptoms were rated significantly higher in terms of frequency and severity for the hypoglycemia aware group (Table 4).
A separate analysis of variance for tremor noticeability, frequency, and severity was performed to compare differences across gender, age, years with diabetes, and physical activity. A Shapiro-Wilk test confirmed that the data did not adhere to the condition of normality $(P<.001)$, possibly because the responses were performed on a 10-point Likert scale.

Table 4. Symptom frequency and severity across hypoglycemia impaired or aware groups.

\begin{tabular}{|c|c|c|c|c|c|c|}
\hline \multirow[t]{2}{*}{ Symptoms } & \multicolumn{3}{|l|}{ Symptom frequency $^{\mathrm{a}}$} & \multicolumn{3}{|l|}{ Symptom severity ${ }^{b}$} \\
\hline & Impaired, mean (SD) & Aware, mean (SD) & $P$ value $^{\mathrm{c}}$ & Impaired, mean (SD) & Aware, mean (SD) & $P$ value $^{\mathrm{c}}$ \\
\hline Tremor & $3.19(1.97)$ & $6.59(2.40)$ & $<.001$ & $2.97(1.84)$ & $6.33(2.4)$ & $<.001$ \\
\hline Headache & $4.49(2.72)$ & $6.30(2.84)$ & $<.001$ & $3.99(2.67)$ & $5.99(2.93)$ & $<.001$ \\
\hline Change in saliva & $3.12(2.23)$ & $5.9(2.82)$ & $<.001$ & $2.92(2.24)$ & $5.76(2.76)$ & $<.001$ \\
\hline Sweating & $4.87(2.67)$ & $7.11(2.41)$ & $<.001$ & $4.46(2.51)$ & $7.14(2.44)$ & $<.001$ \\
\hline Change in body temperature & $4.3(2.52)$ & $7.0(2.55)$ & $<.001$ & $3.86(2.43)$ & $6.73(2.59)$ & $<.001$ \\
\hline Tingly feeling in limbs & $4.61(2.78)$ & $7.01(2.28)$ & $<.001$ & $4.04(2.46)$ & $6.57(2.41)$ & $<.001$ \\
\hline
\end{tabular}

${ }^{a} 1=$ extremely rare, $5=$ neither rare nor frequent, $10=$ extremely frequent.

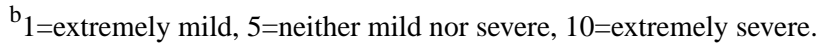

${ }^{\mathrm{c}}$ Mann-Whitney test results.

\section{Effects of Gender}

First, the noticeability of tremors (dependent variable) was assessed across the 2 genders. A Mann-Whitney test revealed a significant difference $(\mathrm{U}=3887 ; P<.001)$, whereby males reported noticing their tremors significantly more than females. In terms of frequency of occurrence, tremors were reported to

be higher in males than in females. Males tended to report more tremors once a day, while females reported more tremors once a month (Table 5). However, this difference was not statistically significant $(\mathrm{U}=4661 ; P=.11)$. The reported severity was significantly different $(\mathrm{U}=4428 ; P=.03)$ between females and males (Table 6). 
Table 5. Frequency of hypoglycemic tremors across genders.

\begin{tabular}{lll}
\hline Charecteristics & Female, $\mathrm{n}(\%)$ & Male, $\mathrm{n}(\%)$ \\
\hline Never & $6(5)$ & $5(6)$ \\
Rarely & $30(23)$ & $18(22)$ \\
Once a month & $29(22)$ & $14(17)$ \\
Once a week & $23(18)$ & $13(16)$ \\
Once every few days & $25(19)$ & $14(17)$ \\
Once a day & $11(9)$ & $13(16)$ \\
More than once a day & $5(4)$ & $6(7)$ \\
Total (N) & 129 & 83 \\
\hline
\end{tabular}

Table 6. Effect of gender on tremor noticeability, frequency, and severity.

\begin{tabular}{|c|c|c|c|c|}
\hline Differences across gender & Participants, $n$ & Median & Mean (SD) & $P$ value \\
\hline \multicolumn{5}{|l|}{ Noticeability $^{\mathbf{a}}$} \\
\hline Gender & & & & $<.001$ \\
\hline Female & 129 & 5 & $4.94(2.55)$ & \\
\hline Male & 83 & 7 & $6.23(2.69)$ & \\
\hline \multicolumn{5}{|l|}{ Frequency $^{\mathbf{b}}$} \\
\hline Gender & & & & .11 \\
\hline Female & 129 & 4 & $4.57(2.63)$ & \\
\hline Male & 83 & 5 & $5.24(2.95)$ & \\
\hline \multicolumn{5}{|l|}{ Severity ${ }^{c}$} \\
\hline Gender & & & & .03 \\
\hline Female & 129 & 4 & $4.26(2.61)$ & \\
\hline Male & 83 & 5 & $5.10(2.80)$ & \\
\hline
\end{tabular}

\footnotetext{
${ }^{\mathrm{a}} 1=$ extremely unnoticeable, $5=$ neither unnoticeable nor noticeable, $10=$ extremely noticeable.

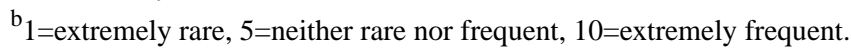

$\mathrm{c}_{1=}=$ extremely mild, $5=$ neither mild nor severe, $10=$ extremely severe.
}

\section{Effects of Age}

The age groups listed in the demographics were divided into 3 groups. Participants were defined as young if their age was between 18 and 30 years, of middle age if they responded as being aged between 31 and 60 years, and of older age if they responded as being aged $\geq 60$ years. The Kruskal-Wallis test showed a significant difference between the 3 groups $\left(\mathrm{H}_{2}=14.56\right.$; $P<.001)$. The older group reported significantly lower noticeability rating compared to both the younger group (median=1.82; SE $0.617 ; P=.01$ ) and middle age group (median=2.166; SE $0.57 ; P<.001$ ). No difference was found between the younger and middle age groups $(P=.66)$.

Differences in the perceived frequency of hypoglycemic tremors were assessed across the 3 age groups. The Kruskal-Wallis test showed no significant difference $\left(\mathrm{H}_{2}=4.2 ; P=.12\right)$ between the younger, middle age, and older groups. However, the older group reported a lower perceived frequency than the other 2 groups, as seen in Figure 1. In particular, the older group did not report any daily tremors; rather, they had a higher number of responses for once a month and never than the other age groups. A similar analysis was performed for the perceived severity of tremors for the 3 age groups. No significant difference was found $\left(\mathrm{H}_{2}=5.371 ; P=.07\right)$ between the younger group, the middle aged group, and the older group even though the older population tended to perceive the severity of their tremors to be low compared with medium for middle age and young respondents. Table 7 shows a summary of these differences. 
Figure 1. Frequency of hypoglycemic tremors across age groups (top: youngest group [18-30 years]; middle: $30-60$ years; bottom: oldest group [ $\geq 60$ years]).

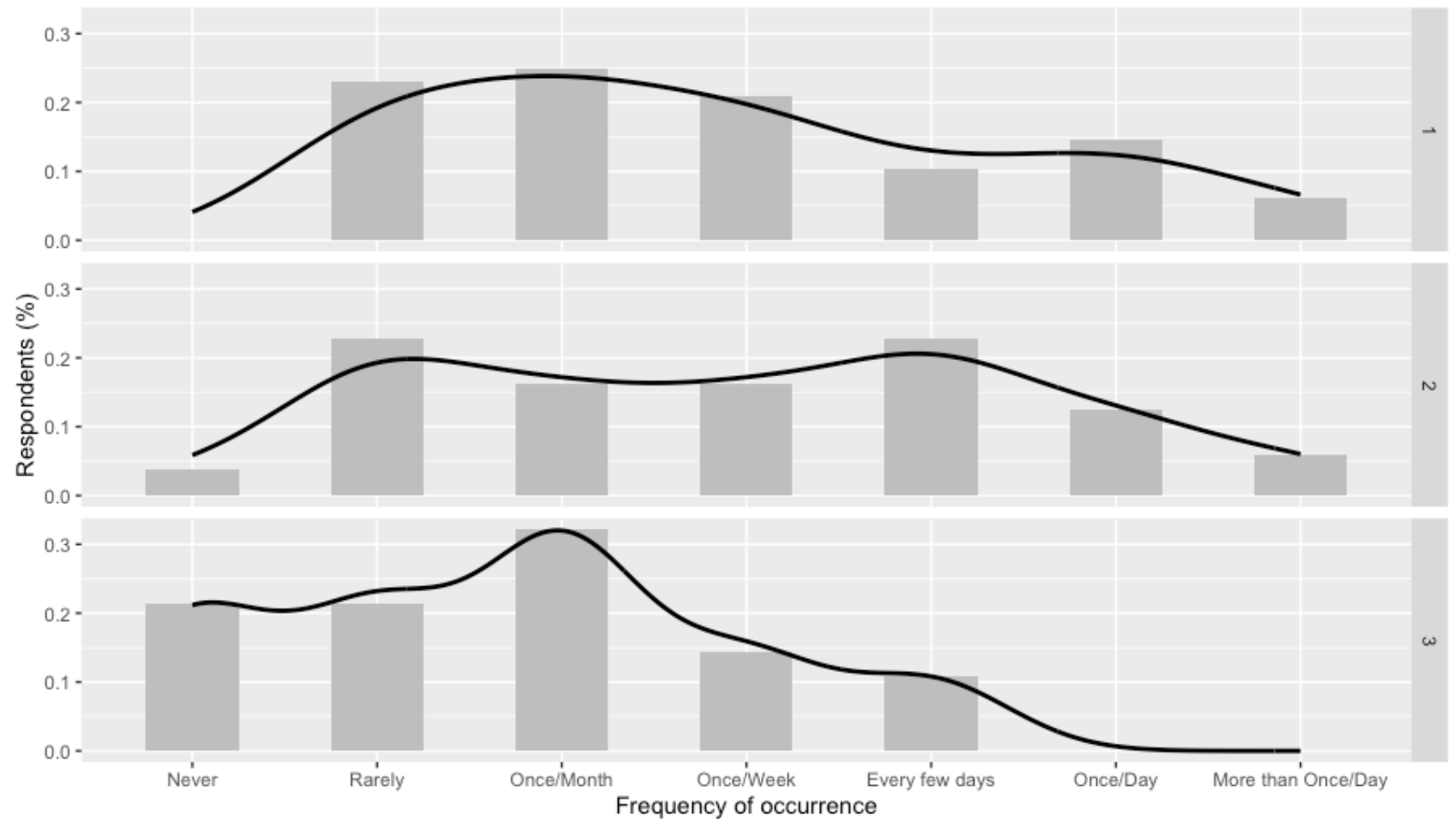

Table 7. Effect of age on tremor noticeability, frequency, and severity.

\begin{tabular}{|c|c|c|c|c|}
\hline Differences across gender & Participants, $\mathrm{n}$ & Mean (SD) & Median & $P$ value \\
\hline \multicolumn{5}{|l|}{ Noticeability $^{\text {a }}$} \\
\hline Age group (years) & & & & $<.001$ \\
\hline $18-30$ & 48 & $5.46(2.32)$ & 5 & \\
\hline $31-60$ & 136 & $5.81(2.64)$ & 6 & \\
\hline$\geq 60$ & 28 & $3.64(2.74)$ & 2.5 & \\
\hline \multicolumn{5}{|l|}{ Frequency $^{b}$} \\
\hline Age group (years) & & & & .12 \\
\hline $18-30$ & 48 & $4.58(2.583)$ & 4.5 & \\
\hline $31-60$ & 136 & $5.09(2.82)$ & 5 & \\
\hline$\geq 60$ & 28 & $3.96(2.76)$ & 3 & \\
\hline \multicolumn{5}{|l|}{ Severity $^{c}$} \\
\hline Age group (years) & & & & .07 \\
\hline $18-30$ & 48 & $4.56(2.74)$ & 4 & \\
\hline $31-60$ & 136 & $4.82(2.71)$ & 5 & \\
\hline$\geq 60$ & 28 & $3.54(2.5)$ & 3 & \\
\hline
\end{tabular}

${ }^{\mathrm{a}} 1=$ extremely unnoticeable, $5=$ neither unnoticeable nor noticeable, $10=$ extremely noticeable.

${ }^{\mathrm{b}} 1=$ extremely rare, $5=$ neither rare nor frequent, $10=$ extremely frequent.

${ }^{\mathrm{c}} 1=$ extremely mild, $5=$ neither mild nor severe, $10=$ extremely severe.

\section{Effects of Years With Diabetes}

A significant difference $\left(\mathrm{H}_{3}=6.322 ; P=.01\right)$ between groups was found with regard to the noticeability of hypoglycemic tremors.
Those who were more recently diagnosed with diabetes $(\leq 1$ year) reported significantly more noticeable tremors (median=1.253; SE 0.479; $P=.05$ ) than those who had been living with diabetes for more than 25 years (Figure 2). 
Figure 2. Frequency of hypoglycemic tremors across years with diabetes groups (top: most recently diagnosed; bottom: longest diagnosed).

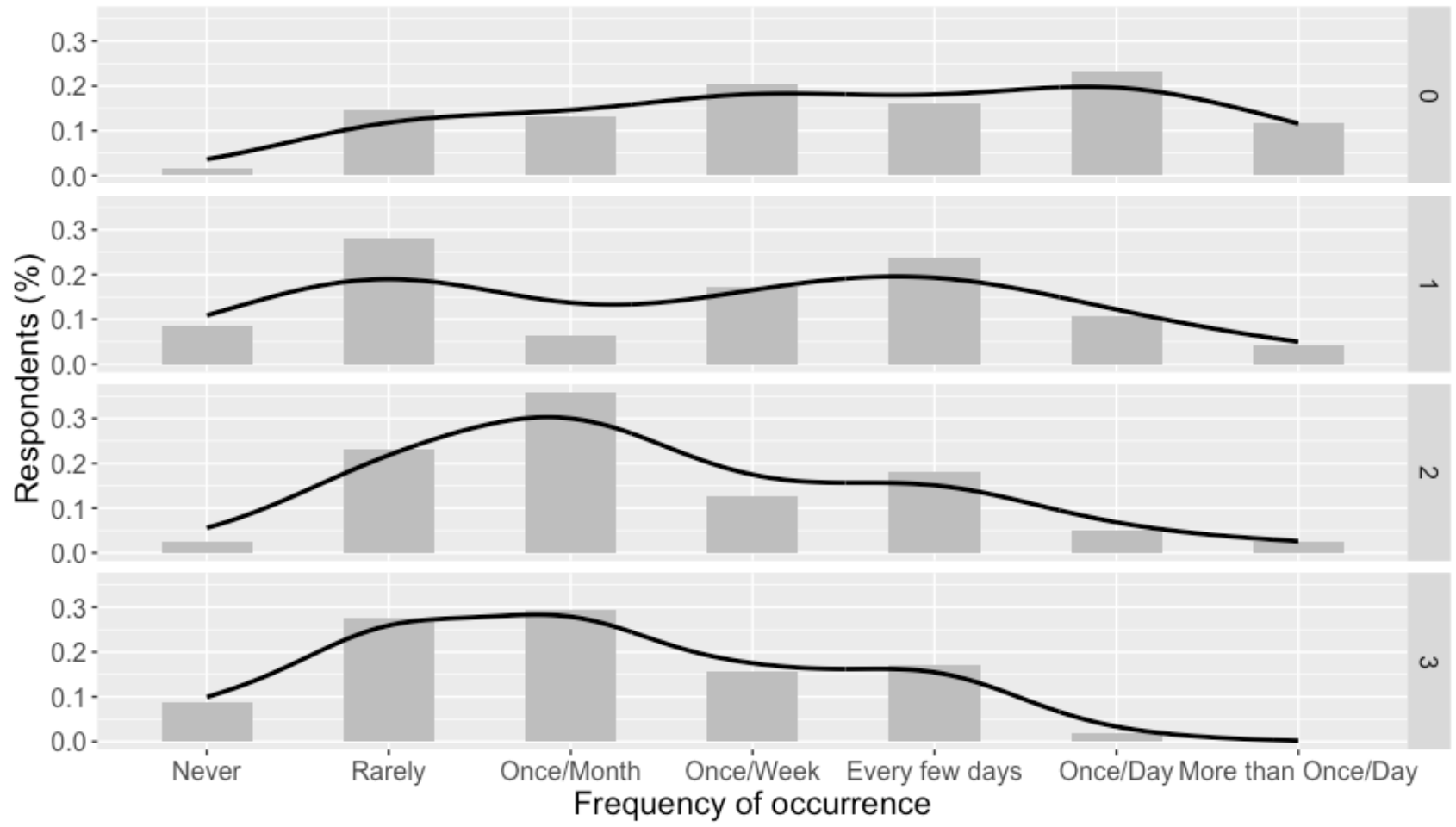

The effect of years living with diabetes was also analyzed over

no significant difference with regard to the severity of these the frequency of hypoglycemic events, but no significant tremors $\left(\mathrm{H}_{3}=7.16 ; P=.07\right.$; Table 8$)$. difference was found $\left(\mathrm{H}_{3}=5.85 ; P=.12\right)$. Similarly, there was 
Table 8. Effect of years living with diabetes on tremor noticeability, frequency, and severity.

\begin{tabular}{|c|c|c|c|c|}
\hline Differences across years with diabetes & Participants, $\mathrm{n}$ & Mean (SD) & Median & $P$ value \\
\hline \multicolumn{5}{|l|}{ Noticeability $^{\mathbf{a}}$} \\
\hline Years with diabetes & & & & .01 \\
\hline$\leq 1$ & 69 & $6.03(2.46)$ & 6 & \\
\hline$>1$ and $\leq 10$ & 46 & $5.44(2.61)$ & 6 & \\
\hline$>10$ and $\leq 25$ & 39 & $5.41(2.67)$ & 5 & \\
\hline$>25$ & 58 & $4.78(2.87)$ & 5 & \\
\hline \multicolumn{5}{|l|}{ Frequency $^{b}$} \\
\hline Years with diabetes & & & & .12 \\
\hline$\leq 1$ & 69 & $5.44(2.89)$ & 5 & \\
\hline$>1$ and $\leq 10$ & 46 & $4.67(2.65)$ & 5 & \\
\hline$>10$ and $\leq 25$ & 39 & $4.87(2.76)$ & 5 & \\
\hline$>25$ & 58 & $4.21(2.65)$ & 4 & \\
\hline \multicolumn{5}{|l|}{ Severity $^{c}$} \\
\hline Years with diabetes & & & & .07 \\
\hline$\leq 1$ & 69 & $5.20(2.79)$ & 5 & \\
\hline$>1$ and $\leq 10$ & 46 & $4.59(2.74)$ & 5 & \\
\hline$>10$ and $\leq 25$ & 39 & $4.51(2.50)$ & 4 & \\
\hline$>25$ & 58 & $3.91(2.62)$ & 3 & \\
\hline
\end{tabular}

${ }^{\mathrm{a}} 1=$ extremely unnoticeable, $5=$ neither unnoticeable nor noticeable, $10=$ extremely noticeable.

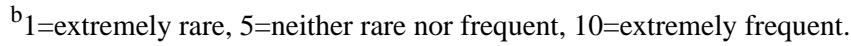

${ }^{c} 1=$ extremely mild, $5=$ neither mild nor severe, $10=$ extremely severe.

\section{Effects of Physical Activity}

The effect of physical activity levels was assessed with regard to the noticeability, frequency, and severity of hypoglycemic tremors, as summarized in Table 9. For noticeability of hypoglycemic tremors, no significant difference was found between the groups $\left(\mathrm{H}_{3}=3.98 ; P=.26\right)$. Similarly, there was no significant effect of activity level on the perceived frequency of hypoglycemic tremors $\left(\mathrm{H}_{3}=4.88 ; P=.18\right)$ or their perceived severity $\left(\mathrm{H}_{3}=6.39 ; P=.09\right)$. 
Table 9. Effect of the level of physical activity on tremor noticeability, frequency, and severity.

\begin{tabular}{|c|c|c|c|c|}
\hline Differences across levels of physical activity & Participants, $\mathrm{n}$ & Mean (SD) & Median & $P$ value \\
\hline \multicolumn{5}{|l|}{ Noticeability $^{\mathbf{a}}$} \\
\hline Level of physical activity & & & & .26 \\
\hline Highly active & 23 & $6.48(2.94)$ & 7 & \\
\hline Active & 65 & $5.17(2.52)$ & 5 & \\
\hline Insufficiently active & 74 & $5.42(2.40)$ & 5.5 & \\
\hline Inactive & 50 & $5.36(3.06)$ & 5 & \\
\hline \multicolumn{5}{|l|}{ Frequency $^{\mathbf{b}}$} \\
\hline Level of physical activity & & & & .18 \\
\hline Highly active & 23 & $5.78(3.06)$ & 6 & \\
\hline Active & 65 & $4.79(2.70)$ & 4 & \\
\hline Insufficiently active & 74 & $4.34(2.50)$ & 5 & \\
\hline Inactive & 50 & $5.18(3.04)$ & 5 & \\
\hline \multicolumn{5}{|l|}{ Severity ${ }^{c}$} \\
\hline Level of physical activity & & & & .09 \\
\hline Highly active & 23 & $5.65(3.01)$ & 5 & \\
\hline Active & 65 & $4.75(2.78)$ & 5 & \\
\hline Insufficiently active & 74 & $4.00(2.40)$ & 4 & \\
\hline Inactive & 50 & $4.76(2.79)$ & 4.5 & \\
\hline
\end{tabular}

${ }^{\mathrm{a}} 1=$ extremely unnoticeable, $5=$ neither unnoticeable nor noticeable, $10=$ extremely noticeable.

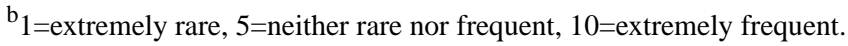

${ }^{c} 1=$ extremely mild, $5=$ neither mild nor severe, $10=$ extremely severe.

\section{Technology Preferences}

When participants were asked if they had used any technology to manage their diabetes, the majority $(150 / 212,70.7 \%)$ reported that they currently used or had used at least one in the past. Among them, 107/150 (71.3\%) used a BG meter, 57/150 (38\%) had used a smartphone app, 41/150 (27.3\%) had used a CGM,

and 49/150 (32.6\%) had used an insulin pump to help them with diabetes self-management. Additionally, around 79/150 (52.7\%) technology users claimed that they used a combination of these technologies. When asked what device brands they used, the most frequent responses, as listed in Table 10, were Medtronic, One Touch, Dexcom, Freestyle Libre, Accu-Check, Bayer Contour, Omnipod, and ReliOn.

Table 10. Device brands reported.

\begin{tabular}{ll}
\hline Brand & Values, $\mathrm{n}(\%)$ \\
\hline Medtronic & $25(16.6)$ \\
One Touch & $24(15.9)$ \\
Dexcom & $17(11.3)$ \\
Freestyle Libre & $10(6.6)$ \\
Accu-Chek & $7(4.6)$ \\
Bayer Contour & $7(4.6)$ \\
OmniPod & $7(4.6)$ \\
ReliOn & $4(2.6)$ \\
True Metrix & $3(2.0)$ \\
Other brands & $9(6.0)$ \\
Don't know/unidentified & $31(20.5)$ \\
\hline
\end{tabular}


Participants were also asked to rate the important features in an ideal smartphone app that would help them manage hypoglycemia, as commonly found in diabetes management apps [39]. Although all features received favorable ratings, continuous glucose monitoring, insulin log, and graphical display of data received the highest ratings (Table 11).

Table 11. Rating of features for a smartphone app to manage diabetes.

\begin{tabular}{lll}
\hline Smartphone app features & Mean $^{\mathrm{a}}(\mathrm{SD})$ & Median \\
\hline Glucose monitor & $7.11(2.74)$ & 8 \\
Insulin log & $6.59(2.8)$ & 7 \\
Graphical display of diabetes data & $6.55(2.85)$ & 7 \\
Log for abnormal sugar levels & $6.54(2.9)$ & 7 \\
Food log & $6.34(2.98)$ & 7 \\
Medication log & $6.16(3.01)$ & 7 \\
Reminders & $6.14(3.06)$ & 6 \\
Educational content & $5.59(2.84)$ & \\
\hline
\end{tabular}

${ }^{\mathrm{a}} 1=$ not important, $5=$ neutral, $10=$ very important.

When asked about the characteristics of a diabetes management tool reported in the literature [40,41], high accuracy of readings, low cost, low maintenance, and 24-hour monitoring received very high ratings (Table 12). Other characteristics such as no effects on daily habits, high privacy and security, customizability, and noninvasiveness also received favorable ratings. When asked for their preferred time of the day to measure BG, morning was most preferred $(187 / 212,88.2 \%)$, followed by evening $(125 / 212,58.9 \%)$, night $(118 / 212,55.6 \%)$, afternoon $(114 / 212,53.8 \%)$, and around noon $(98 / 212,46.2 \%)$.

Table 12. Rating of characteristics for a device to manage diabetes.

\begin{tabular}{lll}
\hline Device characteristics & Mean $^{\mathrm{a}}(\mathrm{SD})$ & Median \\
\hline High accuracy of reading & $8.49(1.88)$ & 9 \\
Low cost & $8.21(2.27)$ & 9 \\
Low maintenance & $8.06(2.18)$ & 9 \\
24-hour monitoring & $8.02(2.28)$ & 8 \\
Doesn't affect daily habits & $7.97(2.16)$ & 8 \\
High privacy and security & $7.85(2.28)$ & 8 \\
Customizability & $7.59(2.36)$ & 8 \\
Not invasive & $7.54(2.57)$ & 7 \\
Sending health data to caregivers & $6.92(2.62)$ & \\
\hline
\end{tabular}

${ }^{\mathrm{a}} 1=$ not important, $5=$ neutral, $10=$ very important.

A modified Comfort Rating Scale (CRS) [42] was used to evaluate the characteristics of a wearable wrist-worn sensor for hypoglycemia management. Although all constructs related to
CRS were rated highly, size and minimized risk for harm received very high ratings followed by emotions felt by the user, social discreteness, and aesthetics (Table 13).

Table 13. Rating of items from the comfort rating scale.

\begin{tabular}{lll}
\hline Wearability characteristics & Mean ${ }^{\mathrm{a}}$ (SD) & Median \\
\hline $\begin{array}{l}\text { Aesthetics (I care about how the device looks) } \\
\text { Social discreteness (I don't want to feel that people look at my wrist and } \\
\text { ask about my device) }\end{array}$ & $6.59(2.85)$ & 7 \\
$\begin{array}{l}\text { Emotions (I don't want to feel anxious wearing it) } \\
\text { Harm (I don't want this device to cause harm to me) }\end{array}$ & $6.76(2.95)$ & 7.5 \\
Size (I want the device to not be bulky) & $7.71(2.67)$ & 9 \\
\hline
\end{tabular}

${ }^{\mathrm{a}} 1=$ not important, $5=$ neutral, $10=$ very important. 


\section{Discussion}

A nationwide survey of 212 patients with type 1 diabetes was conducted to investigate noticeability of hypoglycemic tremors as well as perceived frequency and severity of such tremors among patients. Our findings suggest that while tremors are perceived to be less noticeable, frequent, or severe than other hypoglycemic symptoms such as sweating, changes in body temperature, and headache, in line with the literature [19,21], such hypoglycemic tremors occur at moderate frequency and are being noticed by most patients. Indeed, our study shows that more than $50 \%$ of the respondents encountered hypoglycemic events at least once a week. This is in line with the established evidence suggesting the rate of one to two mild episodes per week among patients with diabetes [43,44]. Given this prevalence, there is a timely need for the detection and mitigation of mild hypoglycemia before becoming severe $[45,46]$. However, according to these results, if tremors are tested and found to be a viable predictor of hypoglycemic onset in future work, tremors should be assessed in conjunction with other symptoms as seen in the study by Shechter et al [47]. In past research, relying solely on body temperature and skin conductance was shown to cause a high number of false alarms, which resulted in the devices being withdrawn from the market $[48,49]$.

In addition to these aggregate trends, our findings show genderand age-specific differences. Although evidence suggests similar occurrence rates of severe hypoglycemia among males and females [50], our findings suggest that males perceive their hypoglycemic tremors more than females. These results are in line with previous findings, which suggest that men were found to have a higher level of adrenaline [51], which is believed to trigger hypoglycemic tremors [52]. In addition, the younger population reported noticing their tremors significantly more than the older population. Similarly, those who had diabetes for a year or less reported noticing their tremors significantly more than those who had diabetes for a longer period. This is in line with previous findings that suggest a radical reduction in the incidence of hypoglycemic symptoms in elderly subjects compared with the younger population [53]. This evidence posits that recurrent hypoglycemia delays the onset of symptoms to lower levels of blood sugar [54] and corroborates previous evidence that patients with a longer history of diabetes may lose sensitivity to hypoglycemic symptoms or perceive such symptoms less [7,8]. These findings further highlight the importance of objective methods for continuous measurement and monitoring of hypoglycemic symptoms in older populations. Participants with higher levels of physical activity also noticed their tremor symptoms more, which may suggest being prone to declining blood sugar levels during and after exercise [55].

While diabetes self-management technologies are gaining popularity, findings from our nationwide survey show that nearly one-third of our sample has not used any technologies to monitor or manage their blood sugar, which suggests low adherence to the basic American Diabetes Association guidelines for the self-management of diabetes [56]. For those who reported using technology, technology adoption was limited to either a blood glucose monitor or a CGM, suggesting the low prevalence of nonintrusive methods for measurement of BG.

As a preliminary step to design a nonintrusive hypoglycemic tremor monitoring tool, we used a patient-centered approach to elicit and document intended users' preferences and expectations for various features, characteristics, and context of use. It is well understood that incorporating such feedback into the design of patient-facing tools facilitates adoption and increases the odds of sustainable usage [57]. For example, while CGM technologies have proven to be reliable [58], these technologies are not affordable, are invasive, and require frequent maintenance [12,59]. These limitations may explain our survey results, where more than $66 \%$ reported not using CGMs. In addition, as evident from our results, for a sensor to be deemed as wearable by patients, it should be comfortable, streamlined in appearance, accurate, affordable, and low maintenance. In addition, any smartphone app that connects to the device must provide a graphical display of the patient's BG data as well as an insulin log. Finally, when participants were asked when they preferred to measure their BG, the most common answers were in the morning and evening, which may suggest expectations for minimal interruptions to professional work. Participants also claimed that they measured their blood sugar approximately four times per day, which is the minimum requirement for T1DM as per several guidelines [38,60]. Although the reported number of measurements ranged from 0 to 10 , approximately half of the respondents claimed that they did not check their blood sugar as advised. This bolsters the argument in support of continuous monitoring technologies $[61,62]$, since reliance on users' memory to sustain usage has proven to be challenging not only for diabetes but also for other chronic diseases $[63,64]$.

Although the study shed light on the nature of perceived hypoglycemic tremor among people with type 1 diabetes and provided information that may guide the design of future tremor-centric interventions, it had some limitations. First, the study only included patients with T1DM, and the results may not generalize to patients with T2DM, especially since hypoglycemia is less common among those patients [65]. In addition, participants were self-identified as T1DM with no objective evidence confirming their condition. Second, the data collected in this study were self-reported. Future work is needed to validate the findings in controlled laboratory environments. Third, since our data were based on Likert scale questions, the analysis was performed using nonparametric tests. However, we believe that our large sample size adds to the robustness of the inference [31]. Finally, a convenience sample was provided using Qualtrics panels. Ideally, a stratified nationwide sample should be used to improve the generalizability of findings.

Regardless of the differences observed in the population studied, this study established the potential efficacy of tremors for a subset of the population as a reliable yet nonintrusive metric for hypoglycemia monitoring technologies and confirms previously reported conclusions [27,47]. The evidence presented in this paper also supports the need for wearable continuous monitoring tools beyond CGMs that are affordable, nonintrusive, and easy to use. Work is in progress to design and evaluate a hypoglycemia monitoring technology that utilizes sensors to 
detect hypoglycemic tremor and mobile health apps to enable self-management.

\section{Acknowledgments}

This research was funded by the National Priorities Research Program award (NPRP 10-1231-160071) from the Qatar National Research Fund (a member of the Qatar Foundation). The statements made herein are solely the responsibility of the authors. The authors would also like to acknowledge the undergraduate students Diego Asturias, Michael Dvorkin, Ghida Dandan, and Skander Helali from Texas A\&M University and Texas A\&M University at Qatar who contributed to the analysis of the data.

\section{Conflicts of Interest}

None declared.

\section{References}

1. Diabetes UK. 2015. Diabetes Prevalence URL: https://www.diabetes.co.uk/diabetes-prevalence.html [accessed 2019-10-15]

2. American Diabetes Association. The Cost of Diabetes URL: https://www.diabetes.org/resources/statistics/cost-diabetes [accessed 2019-07-21]

3. Stokes A, Preston SH. Deaths attributable to diabetes in the United States: comparison of data sources and estimation approaches. PLoS One 2017;12(1):e0170219 [FREE Full text] [doi: 10.1371/journal.pone.0170219] [Medline: 28121997]

4. American Diabetes Association. Hypoglycemia (Low Blood Sugar) URL: http://www.diabetes.org/living-with-diabetes/ treatment-and-care/blood-glucose-control/hypoglycemia-low-blood.html [accessed 2019-07-25]

5. International Hypoglycaemia Study Group. Glucose concentrations of less than $3.0 \mathrm{mmol} / \mathrm{l}$ ( $54 \mathrm{mg} / \mathrm{dL})$ should be reported in clinical trials: a joint position statement of the american diabetes association and the European association for the study of diabetes. Diabetes Care 2017 Jan;40(1):155-157. [doi: 10.2337/dc16-2215] [Medline: 27872155]

6. Gold AE, MacLeod KM, Frier BM. Frequency of severe hypoglycemia in patients with type I diabetes with impaired awareness of hypoglycemia. Diabetes Care 1994 Jul;17(7):697-703. [doi: 10.2337/diacare.17.7.697] [Medline: 7924780]

7. Skrivarhaug T, Bangstad H, Stene LC, Sandvik L, Hanssen KF, Joner G. Long-term mortality in a nationwide cohort of childhood-onset type 1 diabetic patients in Norway. Diabetologia 2006 Feb;49(2):298-305. [doi: 10.1007/s00125-005-0082-6] [Medline: 16365724$]$

8. Kendall DM, Rooney DP, Smets YF, Salazar Bolding L, Robertson RP. Pancreas transplantation restores epinephrine response and symptom recognition during hypoglycemia in patients with long-standing type I diabetes and autonomic neuropathy. Diabetes 1997 Feb;46(2):249-257. [doi: 10.2337/diab.46.2.249] [Medline: 9000702]

9. McCoy RG, van Houten HK, Ziegenfuss JY, Shah ND, Wermers RA, Smith SA. Increased mortality of patients with diabetes reporting severe hypoglycemia. Diabetes Care 2012 Sep;35(9):1897-1901 [FREE Full text] [doi: 10.2337/dc11-2054] [Medline: 22699297]

10. Campbell I. Dead in bed syndrome: a new manifestation of nocturnal hypoglycaemia? Diabet Med 1991 Jan;8(1):3-4. [doi: 10.1111/j.1464-5491.1991.tb01507.x] [Medline: 1826241]

11. Gross TM, Bode BW, Einhorn D, Kayne DM, Reed JH, White NH, et al. Performance evaluation of the MiniMed continuous glucose monitoring system during patient home use. Diabetes Technol Ther 2000;2(1):49-56. [doi: 10.1089/152091500316737] [Medline: 11467320 ]

12. Facchinetti A. Continuous glucose monitoring sensors: past, present and future algorithmic challenges. Sensors (Basel) 2016 Dec 9;16(12):2093 [FREE Full text] [doi: 10.3390/s16122093] [Medline: 27941663]

13. Weitzman ER, Kelemen S, Quinn M, Eggleston EM, Mandl KD. Participatory surveillance of hypoglycemia and harms in an online social network. JAMA Intern Med 2013 Mar 11;173(5):345-351. [doi: 10.1001/jamainternmed.2013.2512] [Medline: 23400234]

14. Polonsky WH, Hessler D. What are the quality of life-related benefits and losses associated with real-time continuous glucose monitoring? A survey of current users. Diabetes Technol Ther 2013 Apr;15(4):295-301. [doi: 10.1089/dia.2012.0298] [Medline: 23427866]

15. García-Lorenzo B, Rivero-Santana A, Vallejo-Torres L, Castilla-Rodríguez I, García-Pérez S, García-Pérez L, et al. Cost-effectiveness analysis of real-time continuous monitoring glucose compared to self-monitoring of blood glucose for diabetes mellitus in Spain. J Eval Clin Pract 2018 Aug;24(4):772-781. [doi: 10.1111/jep.12987] [Medline: 29971893]

16. Wan W, Skandari MR, Minc A, Nathan AG, Winn A, Zarei P, et al. Cost-effectiveness of continuous glucose monitoring for adults with type 1 diabetes compared with self-monitoring of blood glucose: the diamond randomized trial. Diabetes Care 2018 Jun;41(6):1227-1234 [FREE Full text] [doi: 10.2337/dc17-1821] [Medline: 29650803]

17. Rural Health Information Hub. 2017. Chronic Disease in Rural America URL: https://www.ruralhealthinfo.org/topics/ chronic-disease [accessed 2019-06-10]

18. Douthit N, Kiv S, Dwolatzky T, Biswas S. Exposing some important barriers to health care access in the rural USA. Public Health 2015 Jun;129(6):611-620. [doi: 10.1016/j.puhe.2015.04.001] [Medline: 26025176] 
19. Zahed K, Sasangohar F, Mehta R, Erraguntla M, Lawley M, Qaraqe K. Investigating the efficacy of using hand tremors for early detection of hypoglycemic events: a scoping literature review. Proc Hum Factors Ergon Soc Annu Meet 2018 Sep 27;62(1):1211-1215. [doi: 10.1177/1541931218621278]

20. do Amaral CE, Wolf B. Current development in non-invasive glucose monitoring. Med Eng Phys 2008 Jun;30(5):541-549. [doi: 10.1016/j.medengphy.2007.06.003] [Medline: 17942360]

21. Jaap AJ, Jones GC, McCrimmon RJ, Deary IJ, Frier BM. Perceived symptoms of hypoglycaemia in elderly type 2 diabetic patients treated with insulin. Diabet Med 1998 May;15(5):398-401. [doi: 10.1002/(SICI)1096-9136(199805)15:5<398::AID-DIA595>3.0.CO;2-B] [Medline: 9609362]

22. Mühlhauser I, Heinemann L, Fritsche E, von Lennep K, Berger M. Hypoglycemic symptoms and frequency of severe hypoglycemia in patients treated with human and animal insulin preparations. Diabetes Care 1991 Aug;14(8):745-749. [doi: 10.2337/diacare.14.8.745] [Medline: 1954812]

23. Berlin I, Sachon CI, Grimaldi A. Identification of factors associated with impaired hypoglycaemia awareness in patients with type 1 and type 2 diabetes mellitus. Diabetes Metab 2005 Jun;31(3 Pt 1):246-251. [doi: 10.1016/s1262-3636(07)70191-x] [Medline: 16142015]

24. Chiarelli F, Verrotti A, di Ricco L, Altobelli E, Morgese G. Hypoglycaemic symptoms described by diabetic children and their parents. Acta Diabetol 1998 Jul;35(2):81-84. [doi: 10.1007/s005920050108] [Medline: 9747959]

25. Cox DJ, Gonder-Frederick L, Antoun B, Cryer PE, Clarke WL. Perceived symptoms in the recognition of hypoglycemia. Diabetes Care 1993 Feb;16(2):519-527. [doi: 10.2337/diacare.16.2.519] [Medline: 8432227]

26. Heller SR, Macdonald IA, Herbert M, Tattersall RB. Influence of sympathetic nervous system on hypoglycaemic warning symptoms. Lancet 1987 Aug 15;2(8555):359-363. [doi: 10.1016/s0140-6736(87)92382-8] [Medline: 2886822]

27. George E, Harris N, Bedford C, Macdonald IA, Hardisty CA, Heller SR. Prolonged but partial impairment of the hypoglycaemic physiological response following short-term hypoglycaemia in normal subjects. Diabetologia 1995 Oct;38(10):1183-1190. [doi: 10.1007/BF00422367] [Medline: $\underline{\text { 8690170] }}$

28. von Elm E, Altman DG, Egger M, Pocock SJ, Gøtzsche PC, Vandenbroucke JP, STROBE Initiative. The strengthening the reporting of observational studies in epidemiology (STROBE) statement: guidelines for reporting observational studies. Ann Intern Med 2007 Oct 16;147(8):573-577. [doi: 10.7326/0003-4819-147-8-200710160-00010] [Medline: 17938396]

29. Cryer PE. Symptoms of hypoglycemia, thresholds for their occurrence, and hypoglycemia unawareness. Endocrinol Metab Clin North Am 1999 Sep;28(3):495-500. [doi: 10.1016/s0889-8529(05)70084-0] [Medline: 10500927]

30. Mayo Clinic. 2018. Diabetic hypoglycemia: Overview URL: https://www.mayoclinic.org/diseases-conditions/ diabetic-hypoglycemia/symptoms-causes/syc-20371525 [accessed 2019-11-13]

31. Jamieson S. Likert scales: how to (ab)use them. Med Educ 2004 Dec;38(12):1217-1218. [doi: 10.1111/j.1365-2929.2004.02012.x] [Medline: 15566531$]$

32. Duffin E. Statista. 2017. Total Population in the United States by Gender From 2010 to 2024 URL: https://www.statista.com/ statistics/737923/us-population-by-gender/ [accessed 2019-11-17]

33. Census Reporter: Making Census Data Easy to Use. 2018. American Community Survey (ACS) URL: https://www. census.gov/programs-surveys/acs [accessed 2019-11-17]

34. Holst A. Statista. 2019. Mobile OS market share in the US 2019 URL: https://www.statista.com/statistics/266572/ market-share-held-by-smartphone-platforms-in-the-united-states/ [accessed 2019-11-17]

35. Pew Research Center. 2019. Mobile Fact Sheet URL: https://www.pewresearch.org/internet/fact-sheet/mobile/ [accessed 2019-11-17]

36. Statistical Atlas. 2018. The Demographic Statistical Atlas of the United States URL: https://statisticalatlas.com/United-States/ Educational-Attainment [accessed 2019-11-17]

37. Office of Disease Prevention and Health. 2008. 2008 Physical Activity Guidelines URL: https://health.gov/paguidelines/ 2008/chapter4.aspx [accessed 2019-09-05]

38. Mayo Clinic. 2018. Blood Sugar Testing: Why, When and How URL: https://www.mayoclinic.org/diseases-conditions/ diabetes/in-depth/blood-sugar/art-20046628 [accessed 2019-10-20]

39. Jimenez G, Lum E, Car J. Examining diabetes management apps recommended from a Google search: content analysis. JMIR Mhealth Uhealth 2019 Jan 16;7(1):e11848 [FREE Full text] [doi: 10.2196/11848] [Medline: 30303485]

40. American Diabetes Association. Diabetes technology. Diabetes Care 2019 Jan;42(Suppl 1):S71-S80. [doi: 10.2337/dc19-S007] [Medline: $\underline{30559233]}$

41. Wahowiak L. Diabetes Forecast. 2016. Diabetes Devices: Favorite Features URL: http://www.diabetesforecast.org/2016/ mar-apr/diabetes-devices-favorite-features.html [accessed 2019-11-15]

42. Knight J, Baber C, Schwirtz A, Bristow H. The Comfort Assessment of Wearable Computers. In: Proceedings of the Sixth International Symposium on Wearable Computers. 2002 Presented at: SWC'02; October 10, 2002; Seattle, WA, USA. [doi: 10.1109/iswc.2002.1167220]

43. Leese GP, Wang J, Broomhall J, Kelly P, Marsden A, Morrison W, DARTS/MEMO Collaboration. Frequency of severe hypoglycemia requiring emergency treatment in type 1 and type 2 diabetes: a population-based study of health service resource use. Diabetes Care 2003 Apr;26(4):1176-1180. [doi: 10.2337/diacare.26.4.1176] [Medline: 12663593] 
44. Ovalle F, Fanelli CG, Paramore DS, Hershey T, Craft S, Cryer PE. Brief twice-weekly episodes of hypoglycemia reduce detection of clinical hypoglycemia in type 1 diabetes mellitus. Diabetes 1998 Sep;47(9):1472-1479. [doi: 10.2337/diabetes.47.9.1472] [Medline: 9726237]

45. Cryer PE. Severe hypoglycemia predicts mortality in diabetes. Diabetes Care 2012 Sep;35(9):1814-1816. [doi: 10.2337/dc12-0749] [Medline: 22923682]

46. MacLeod KM, Hepburn DA, Frier BM. Frequency and morbidity of severe hypoglycaemia in insulin-treated diabetic patients. Diabet Med 1993 Apr;10(3):238-245. [doi: 10.1111/j.1464-5491.1993.tb00051.x] [Medline: $\underline{8485955]}$

47. Schechter A, Eyal O, Zuckerman-Levin N, Amihai-Ben-Yaacov V, Weintrob N, Shehadeh N. A prototype of a new noninvasive device to detect nocturnal hypoglycemia in adolescents with type 1 diabetes--a pilot study. Diabetes Technol Ther 2012 Aug;14(8):683-689. [doi: 10.1089/dia.2012.0002] [Medline: 22690891]

48. Skladnev VN, Ghevondian N, Tarnavskii S, Paramalingam N, Jones TW. Clinical evaluation of a noninvasive alarm system for nocturnal hypoglycemia. J Diabetes Sci Technol 2010 Jan 1;4(1):67-74 [FREE Full text] [doi: 10.1177/193229681000400109] [Medline: 20167169]

49. Therapeutic Goods Administration (TGA). 2013. HypoMon Sleep-Time Hypoglycaemic Monitor URL: https://www. tga.gov.au/alert/hypomon-sleep-time-hypoglycaemic-monitor [accessed 2018-01-06]

50. Cryer PE. Are gender differences in the responses to hypoglycemia relevant to iatrogenic hypoglycemia in type 1 diabetes? J Clin Endocrinol Metab 2000 Jun;85(6):2145-2147. [doi: 10.1210/jcem.85.6.6659] [Medline: 10852443]

51. Fanelli C, Pampanelli S, Epifano L, Rambotti AM, Ciofetta M, Modarelli F, et al. Relative roles of insulin and hypoglycaemia on induction of neuroendocrine responses to, symptoms of, and deterioration of cognitive function in hypoglycaemia in male and female humans. Diabetologia 1994 Aug;37(8):797-807. [doi: 10.1007/BF00404337] [Medline: 7988782]

52. Cryer PE. Mechanisms of hypoglycemia-associated autonomic failure and its component syndromes in diabetes. Diabetes 2005 Dec;54(12):3592-3601 [FREE Full text] [doi: 10.2337/diabetes.54.12.3592] [Medline: 16306382]

53. McAulay V, Deary IJ, Frier BM. Symptoms of hypoglycaemia in people with diabetes. Diabet Med 2001 Sep;18(9):690-705. [doi: 10.1046/j.1464-5491.2001.00620.x] [Medline: 11606166]

54. Frier BM. Morbidity of hypoglycemia in type 1 diabetes. Diabetes Res Clin Pract 2004 Sep;65(Suppl 1):S47-S52. [doi: 10.1016/j.diabres.2004.07.008] [Medline: $\underline{15315871]}$

55. Younk LM, Mikeladze M, Tate D, Davis SN. Exercise-related hypoglycemia in diabetes mellitus. Expert Rev Endocrinol Metab 2011 Jan 1;6(1):93-108 [FREE Full text] [doi: 10.1586/eem.10.78] [Medline: 21339838]

56. Campbell A. Diabetes Self-Management Magazine. 2019. Blood Sugar Chart: What's the Normal Range for Blood Sugar? URL: https://www.diabetesselfmanagement.com/managing-diabetes/blood-glucose-management/blood-sugar-chart/ [accessed 2019-10-20]

57. Gåfvels C, Lithner F, Börjeson B. Living with diabetes: relationship to gender, duration and complications. A survey in northern Sweden. Diabet Med 1993 Oct;10(8):768-773. [doi: 10.1111/j.1464-5491.1993.tb00162.x] [Medline: $\underline{\text { 8261761] }}$

58. Mazze RS, Strock E, Borgman S, Wesley D, Stout P, Racchini J. Evaluating the accuracy, reliability, and clinical applicability of continuous glucose monitoring (CGM): is CGM ready for real time? Diabetes Technol Ther 2009 Jan;11(1):11-18. [doi: 10.1089/dia.2008.0041] [Medline: 19132850]

59. Chua B, Desai SP, Tierney MJ, Tamada JA, Jina AN. Effect of microneedles shape on skin penetration and minimally invasive continuous glucose monitoring in vivo. Sens Actuators Phys 2013 Dec;203:373-381. [doi: 10.1016/j.sna.2013.09.026]

60. WebMD. Home Blood Sugar Testing URL: https://www.webmd.com/diabetes/home-blood-glucose-testing [accessed 2019-10-20]

61. Juvenile Diabetes Research Foundation Continuous Glucose Monitoring Study Group, Tamborlane WV, Beck RW, Bode BW, Buckingham B, Chase HP, et al. Continuous glucose monitoring and intensive treatment of type 1 diabetes. N Engl J Med 2008 Oct 2;359(14):1464-1476. [doi: 10.1056/NEJMoa0805017] [Medline: 18779236]

62. Klonoff DC. Continuous glucose monitoring: roadmap for 21st century diabetes therapy. Diabetes Care 2005 May;28(5):1231-1239. [doi: $10.2337 /$ diacare.28.5.1231] [Medline: 15855600$]$

63. Zogg JB, Woods SP, Sauceda JA, Wiebe JS, Simoni JM. The role of prospective memory in medication adherence: a review of an emerging literature. J Behav Med 2012 Feb;35(1):47-62 [FREE Full text] [doi: 10.1007/s10865-011-9341-9] [Medline: 21487722]

64. Insel KC, Einstein GO, Morrow DG, Hepworth JT. A multifaceted prospective memory intervention to improve medication adherence: design of a randomized control trial. Contemp Clin Trials 2013 Jan;34(1):45-52 [FREE Full text] [doi: 10.1016/j.cct.2012.09.005] [Medline: 23010608]

65. American Diabetes Association. Insulin Basics URL: https://www.diabetes.org/diabetes/medication-management/ insulin-other-injectables/insulin-basics [accessed 2019-10-20]

\section{Abbreviations}

BG: blood glucose

CRS: Comfort Rating Scale

CGM: continuous glucose monitor 
ODPHP: Office of Disease Prevention and Health Promotion

T1DM: type 1 diabetes mellitus

T2DM: type 2 diabetes mellitus

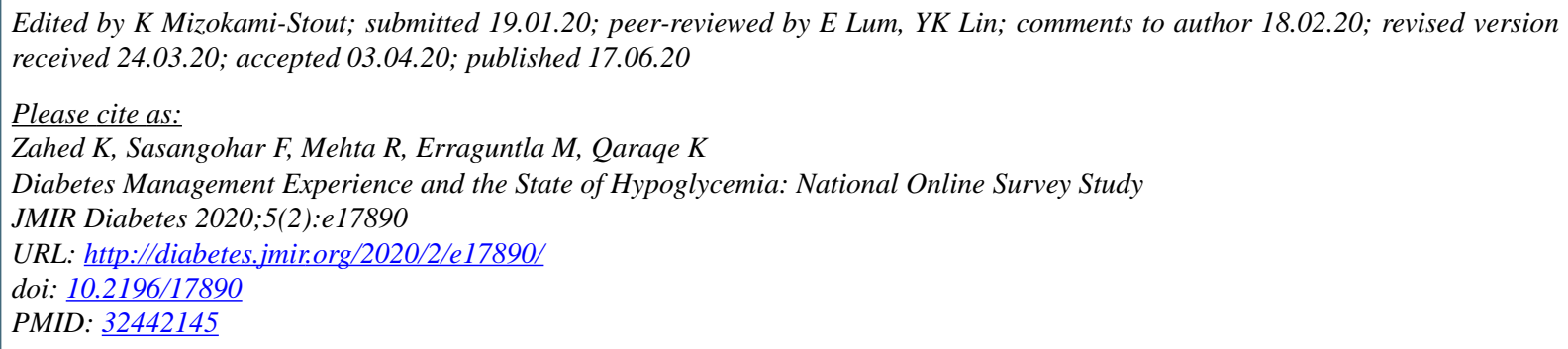

CKarim Zahed, Farzan Sasangohar, Ranjana Mehta, Madhav Erraguntla, Khalid Qaraqe. Originally published in JMIR Diabetes (http://diabetes.jmir.org), 17.06.2020. This is an open-access article distributed under the terms of the Creative Commons Attribution License (https://creativecommons.org/licenses/by/4.0/), which permits unrestricted use, distribution, and reproduction in any medium, provided the original work, first published in JMIR Diabetes, is properly cited. The complete bibliographic information, a link to the original publication on http://diabetes.jmir.org/, as well as this copyright and license information must be included. 